\title{
Understanding partial bed-load transport: Experiments and stochastic model analysis
}

\author{
HongGuang Sun ${ }^{\mathrm{a}}$, Dong Chen ${ }^{\mathrm{b}, *}$, Yong Zhang ${ }^{\mathrm{c}}$, Li Chen ${ }^{\mathrm{d}, \mathrm{e}}$ \\ ${ }^{a}$ State Key Laboratory of Hydrology-Water Resources and Hydraulic Engineering, College of Mechanics and Materials, Hohai University, Nanjing, China

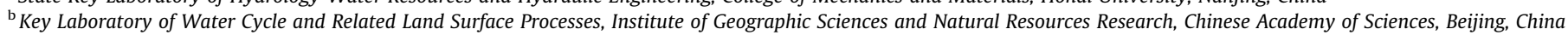

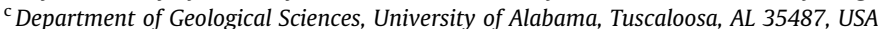 \\ ${ }^{\mathrm{d}}$ Division of Hydrologic Sciences, Desert Research Institute, Las Vegas, NV 89119, USA \\ e State Key Laboratory of Hydrology-Water Resources and Hydraulic Engineering, Hohai University, Nanjing, China
}

\section{A R T I C L E I N F O}

\section{Article history:}

Received 4 August 2014

Received in revised form 17 November 2014

Accepted 22 November 2014

Available online 29 November 2014

This manuscript was handled by Andras

Bardossy, Editor-in-Chief, with the

assistance of Purna Chandra Nayak,

Associate Editor

\section{Keywords:}

Partial bed-load transport

Anomalous transport

Scale dependent

Fractional derivative

\section{S U M M A R Y}

The complex dynamics of partial bed-load transport in a series of well-controlled laboratory experiments are explored systematically and simulated by a stochastic model in this study. Flume experiments show that the leading front of bed-load on a 20-m-long, mixed-size gravel-bed moves anomalously, where the transient transport rate of the accelerating front varies with the observation time scale. In addition, observations show that moving particles may experience bimodal transport (i.e., coexistence of long trapping time and large jump length) related to bed coarsening and the formation of clusters on a heterogeneous gravel-bed, which is distinguished from the traditional theory of hiding-exposing interactions among mixed-size particles. A fractional derivative model is finally applied to characterize the overall behavior of partial bed-load transport, including the coexistence of the sub-diffusion and non-local feature caused by turbulence and the micro-relief within an armor layer.

(c) 2014 Elsevier B.V. All rights reserved.

\section{Introduction}

Despite substantial efforts that have been made over the last two decades, our ability to estimate bed-load flux in a turbulent system remains inadequate (Lane, 1947; Lee and Odgaard, 1987). The error in prediction sometimes becomes unacceptable in gravel-bed rivers where the measured transport rates often differ by one to two orders of magnitude from predictions using the standard formulae (Bathurst, 2007; Barry et al., 2004). One of the major obstacles is the poor understanding of the degree to which a river-bed is coarsened or armored (Wilcock and DeTemple, 2005; Barry et al., 2004; Karim and Holly, 1986; Wu et al., 2004). In a mixed-size gravel-bed river, the bed is often sorted such that the surface composition is coarser than the substrate (Whiting and King, 2003; Wilcock and Crowe, 2003; Parker and Sutherland, 1990; Parker, 1990). In addition, cluster structures are often observed on riverbeds composed of particles with a wide range of size distributions, which could significantly alter bed-load transport rates (Strom et al., 2004; Wittenberg and Newson, 2005). The error caused by ignoring this bed-coarsening effect will be most significant if the flow is only able to transport

\footnotetext{
* Corresponding author. Tel.: +861064889766.

E-mail address: dchen@igsnrr.ac.cn (D. Chen).
}

a portion of the particles on the bed surface, i.e., the process of partial transport (Janssen, 2010; Shaheen and Diplas, 2005). Partial transport is the dominant transport condition in many gravel-bed rivers (Wilcock and McArdell, 1997).

In addition, most existing formulae on bed-load transport deal with the average transport rate (mathematic expectation) of major particles as a whole and ignore its variance (Chien and Wan, 1999). This simplification is sometimes acceptable in practice, but not always. Large errors or deviations may arise from the lack of comprehensive explanation of the entire stochastic process. Fig. 1 indicates the bed-load transport on the mixed-size gravel-beds conducted in experiments exhibits substantial randomness, and even sophisticated formulae that include the mechanisms of surfacebased transport (e.g., Wilcock and Crowe, 2003) or the hidingexposure correction (e.g., Wu et al., 2000) cannot satisfactorily estimate the sediment flux. Therefore anomalous particle behaviors, such as coexistence of slower movement due to cluster blocking and faster movement due to the high-speed belts among those clusters (which will be discussed later), should be considered to fully understand the partial transport process of bed-load.

Both super- and sub-diffusive anomalous transport of bed-load have been discussed recently. For example, Nikora et al. (2002), Hill et al. (2010), Bradley et al. (2010), and Martin et al. (2012) 


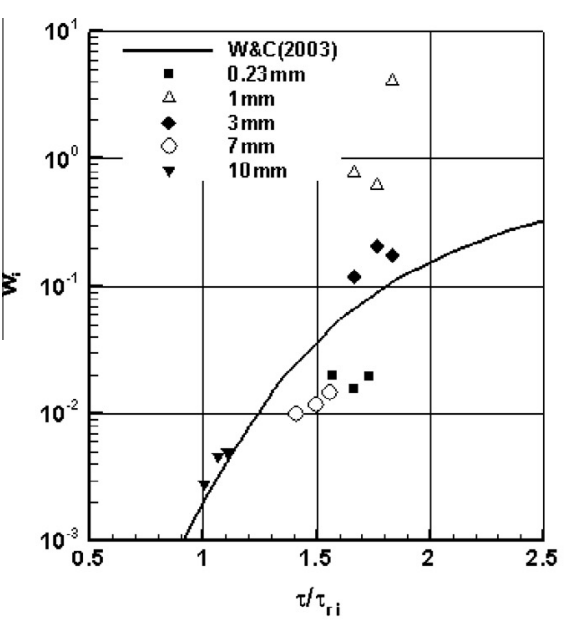

(a)

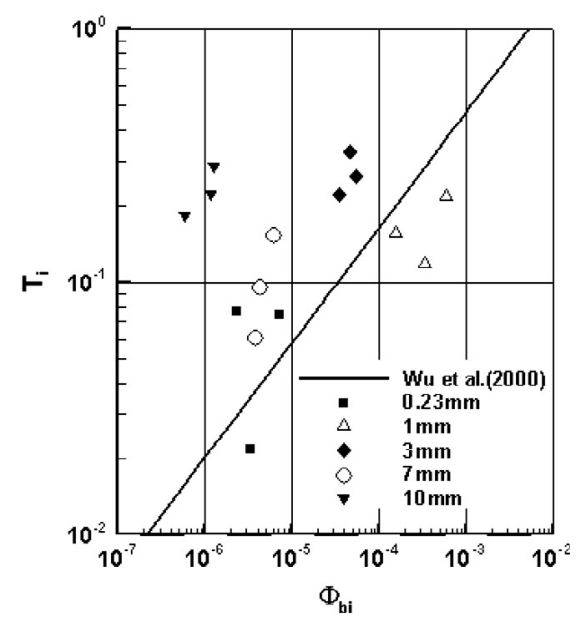

(b)

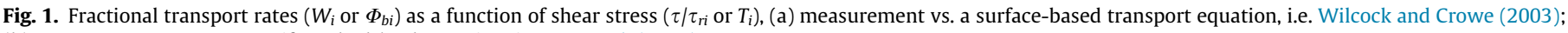
(b) measurement vs. a non-uniform bed-load equation, i.e. Wu et al. (2000).

investigated the super-dispersive displacement of bed-load sediment. These studies further explored the main mechanism of super-dispersion, including the particle inertia within high stream velocities and the mixed displacement for sediment particles with different sizes. In addition, sub-dispersion in sediment particle motion caused by sheltering or burial of particles in the bed has also been discussed (Nikora et al., 2002; Lajeunesse et al., 2010; Martin et al., 2012). Furthermore, the transition from super-dispersion to sub-diffusion was observed and modeled by Martin et al. (2012). Zhang et al. (2012) proposed a tempered random walk model to describe the transition from super-dispersion to sub-dispersion, and the final convergence to Fickian dispersion for bedload sediment transport.

However, more experiments and stochastic model analysis are still needed to understand the nature of the anomalous bed-load sediment transport. One of the major challenges is the particle size effect on anomalous dynamics, which has not been tackled by previous studies. Besides, none of the aforementioned stochastic studies has investigated the movement of bed-load front, which may be critical for bed-load transport estimation in practice. For instance, sand or silt supply to an armored gravel-bed river might remarkably increase due to events such as wildfire, reservoir flushing, and dam removal (Wilcock et al., 2001). The water-consumers at downstream are highly concerned with the time at which the front of the finer material will arrive at water-intake structures.

In the present study, experimental results provide evidences for the memory and non-locality properties of bed-load transport that may be inherent in a mixed-size gravel-bed during partial transport. In addition, the study offers insights into describing the elusive processes with numerical solutions of the fractional derivative equations (FDEs), in which time fractional derivative corresponds to history memory and spatial fractional derivative refers to non-locality properties of bed-load transport.

\section{Experimental setup}

Non-uniform bed-load transport and bed coarsening experiments have been conducted by many researchers including Gessler (1970), Little and Meyer (1976), Garde et al. (1977), Sutherland and Williman (1977), Proffitt (1980), Parker et al. (1982), Parker and Wilcock (1993), Wilcock (2001), Diplas and Shaheen (2007), and Mao et al. (2011), but none of these studies has addressed the anomalous dynamics of bed-load transport. As discussed above, anomalous transport tends to arise on a mixedsize gravel-bed during low Shields stress scour, i.e., partial transport. The present experiments are designed to explore the dynamics of bed-load transport by both tracing the displacement of bedload front with time and examining the spatial distribution of bedload particles.

In this study, the experimental sand/gravel mixture was prepared by blending grains of five size fractions, i.e. $0.45 \mathrm{~mm}$, $1 \mathrm{~mm}, 3 \mathrm{~mm}, 7 \mathrm{~mm}$, and $17 \mathrm{~mm}$, with the proportions shown in Table 1. In terms of the American Geophysical Union (AGU) standard classification (Subcommittee on Sediment Terminology of AGU, 1947), the first fraction falls into the category of fine to medium sand, the second belongs to coarse sand, and the others are gravels. The experiments were conducted in a tilting glass-wall flume with a dimension of $50 \mathrm{~m} \times 1 \mathrm{~m} \times 1.2 \mathrm{~m}$ for the length, width and depth (Fig. 2). The effective maximum flume length for sediment transport is $20 \mathrm{~m}$. A carefully leveled bed consisting of a mixture of white color grains was then set to a constant slope of 0.004 . The inflow discharge measured by an electromagnetic flow meter varied from $120 \mathrm{l} / \mathrm{s}$ to $140 \mathrm{l} / \mathrm{s}$ (Table 2).

Instead of a closed system with zero sediment feeding which depends on the initial condition and might result in a "static armor layer" (Mao et al., 2011; Bettess and Frangipane, 2003; Wilcock, 2001; Gessler, 1970), the present experiment was conducted in an open system with continuous sediment feeding (Mao et al., 2011; Diplas and Shaheen, 2007). For example, in the experiment of Run 1, moving grains were collected by a trap placed at the outlet of the flume and weighted in an interval of $15 \mathrm{~min}$ and then reloaded at the inlet. After a relatively constant or quasi-equilibrium transport flux was obtained (which was measured at $0.84 \mathrm{~g} / \mathrm{s}$ ), a small portion of the trapped sediment was dried, sieved, and weighted. Meanwhile the sediment circulation was maintained. When obtaining the weight proportions of all the size fractions, we started to feed new sediment particles continuously at the inlet

Table 1

Experimental sand/gravel mixture.

\begin{tabular}{llll}
\hline Fractions & $d_{m}(\mathrm{~mm})$ & Weight $(\%)$ & Sieve opening sizes $(\mathrm{mm})$ \\
\hline 1 & 0.45 & 10 & $0.25-0.8$ \\
2 & 1.0 & 15 & $0.6-1.25$ \\
3 & 3.0 & 25 & $1-5$ \\
4 & 7.0 & 25 & $5-10$ \\
5 & 17.0 & 25 & $15-20$ \\
\hline
\end{tabular}




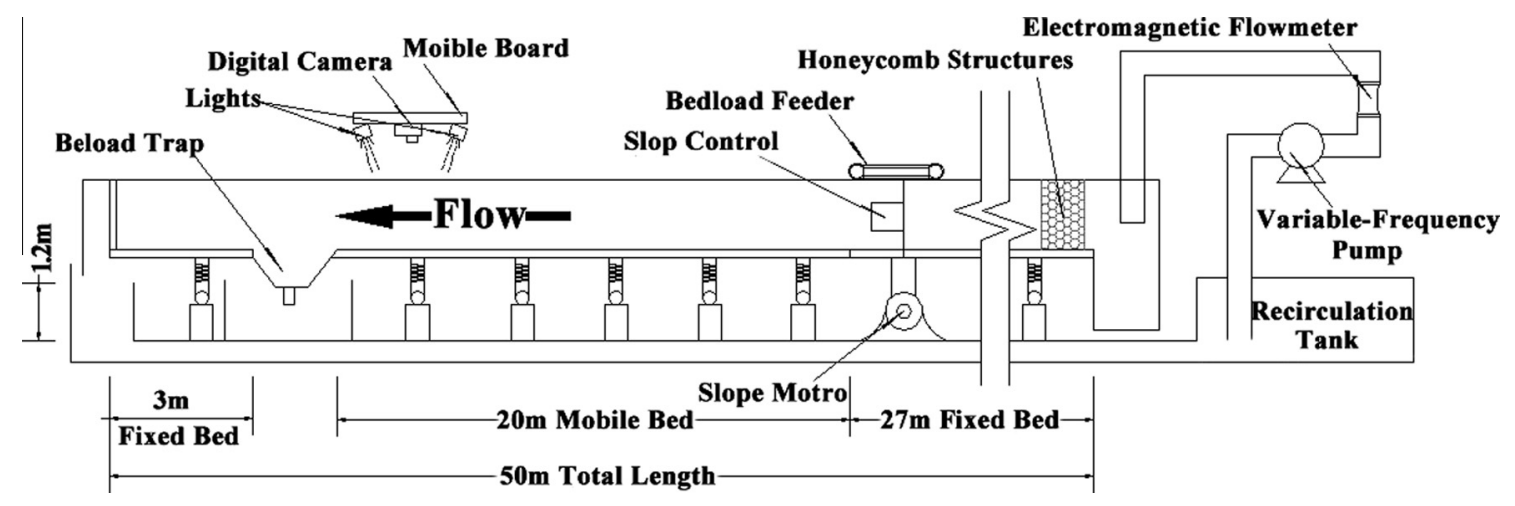

Fig. 2. Schematic of flume (drawing not to scale).

Table 2

Inflow and duration of the experiments.

\begin{tabular}{lllll}
\hline $\begin{array}{l}\text { Experiment } \\
\text { runs }\end{array}$ & $\begin{array}{l}d_{m} \\
(\mathrm{~mm})\end{array}$ & $\begin{array}{l}\text { Flow discharge } \\
(\mathrm{l} / \mathrm{s})\end{array}$ & $\begin{array}{l}\text { Flow depth } \\
(\mathrm{cm})\end{array}$ & $\begin{array}{l}\text { Duration } \\
\text { (minutes) }\end{array}$ \\
\hline $1(\mathrm{~A})$ & 1 & 120 & 15.22 & 155 \\
$1(\mathrm{~B})$ & 1 & 120 & 15.32 & 355 \\
$2(\mathrm{~A})$ & 3 & 130 & 16.13 & 270 \\
$2(\mathrm{~B})$ & 3 & 130 & 16.23 & 430 \\
$3(\mathrm{~A})$ & 7 & 140 & 16.78 & 65 \\
$3(\mathrm{~B})$ & 7 & 140 & 16.72 & 345 \\
\hline
\end{tabular}

rather than recirculation. The new blend of grains were fed at the same rate of $0.84 \mathrm{~g} / \mathrm{s}$ (submerged weight) and the same proportion of the last trapped sediment particles, except that the $1 \mathrm{~mm}$ white particles were replaced by the same amount of $1 \mathrm{~mm}$ black particles in the mixture to examine the movement of $1 \mathrm{~mm}$ particles. Finally, the front and spatial distribution of $1 \mathrm{~mm}$ black particles on a white bed can be conveniently traced using an image-processing technique. The same procedures were used for the $3 \mathrm{~mm}$ and $7 \mathrm{~mm}$ particles in Runs 2 and 3.

Two series of flume experiments namely series-A and series-B were conducted (Table 2). In the series-A experiments, we recorded the movement of sediment front and stopped the water when the sediment front reached the outlet. In the series-B experiments, we used the same coarsened bed and reproduced the flow condition as those in the series-A experiments, and we fed the tracer particles with colors distinct from the ones used in the series-A experiments. In particular, we ran the series-B flume experiments much longer, in order to observe the sediment transport behavior at a larger time scale.

\section{Experimental results and discussion}

\subsection{Front movement of tracing particles}

Fig. 3 shows the displacement of sediment front with time. The anomaly of front transport is evaluated against the expression of $x=\lambda t^{\gamma}$. Since constant flow discharges were adopted in the experiments, $\gamma \approx 1$ means that a convection process dominates the transport at the moment. The factor $\lambda$ is related to the mean velocity of moving particles. Fig. 3 indicates that the bed-load front on a mixed-size gravel bed travels anomalously, where the transient transport rates vary with the observation time scale and the sediment size. Different power-law trends at the early time (red line), the late time (blue line), and the entire observation time (the dashed line) can be observed from Fig. 3. Considering convection always plays its role more or less throughout experiments, sub-diffusion phenomena exist for all the three size particles, particularly noticeable for $7 \mathrm{~mm}$ particles which has $\gamma=0.39$ in general.
Observations also evidenced relatively continuous movement of the leading front of $7 \mathrm{~mm}$ particles in the rear part of the flume $(\gamma \approx 1)$, while the displacement of the leading $1 \mathrm{~mm}$ particles was composed of many intermittent bursts and the temporal intervals between two bursts increased toward downstream. The increased resting time of the leading $1 \mathrm{~mm}$ particles is most likely caused by the hiding effect exerted by the armor layer, while the bursting behavior of the $1 \mathrm{~mm}$ particles might be related to the observed collapse and reconstruction of local bed clusters (which will be discussed later). The $3 \mathrm{~mm}$ particles exhibited a travel behavior between the $1 \mathrm{~mm}$ and $7 \mathrm{~mm}$ particles, which is more similar to the $7 \mathrm{~mm}$ particles.

Another conclusion drawn herein is that a remarkably large time domain is needed for the mixed-size bed-load transport experiment to well capture the exhaustive feature of the elusive processes. In other words, to observe a complete anomalous diffusion process, one has to wait till a large number of small-probability events take effect.

\subsection{Spatial distribution of tracing sediment}

Fig. 4 shows the normalized spatial distribution of colored sediment in the sampling cycle for the series-A experiments. The $Y$ coordinate in Fig. 4 presents the normalized quantity of colored (tracing) particles at location $x$ on the flume-bed. Those colored particles were photographed at intervals of $0.1 \mathrm{~m}$ along the flume and counted using Image (an image-processing software); afterwards their quantities were divided by their maximum value (normally 1-2 m downstream the feeding cross-section depending on flow and particle sizes). The spatial distribution of colored sediment exhibits a heavy leading front (toward the downstream), especially for the $1 \mathrm{~mm}$ particles. For comparison purposes, three curves calculated by the classical stochastic advection-dispersion equation (ADE) are also drawn in Fig. 4.

The ADE is expressed as below:

$\frac{\partial S}{\partial t}=-v \frac{\partial S}{\partial x}+D \frac{\partial^{2} S}{\partial x^{2}}$

where $S(x, t)$ is the probability density function (PDF) of particles quantity distribution; $t$ denotes the time; $x(0<x<20 \mathrm{~m})$ denotes the space coordinate; and $v$ and $D$ represent the particle mean velocity and diffusive coefficient, respectively. The value of $v$ is obtained by computing the mean velocity of all measured particles with the following equation:

$v=\frac{\frac{1}{N} \sum_{i=1}^{M} n_{i} l_{i}}{T}$

where $N$ is the total number of particles, $M$ is the number of spatial intervals, $n_{i}$ is the amount of particles at the $i$-th spatial interval, $l_{i}$ is 


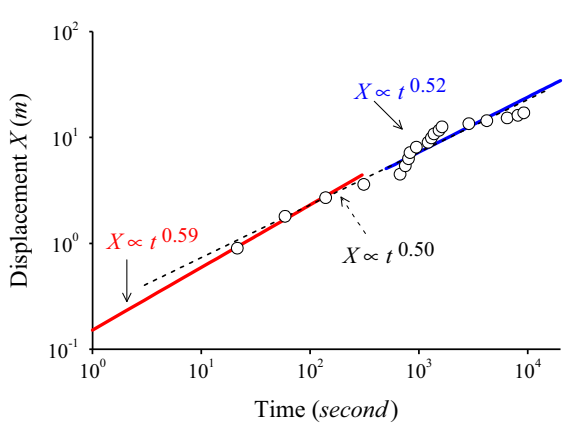

(a) Sediment size $1 \mathrm{~mm}$

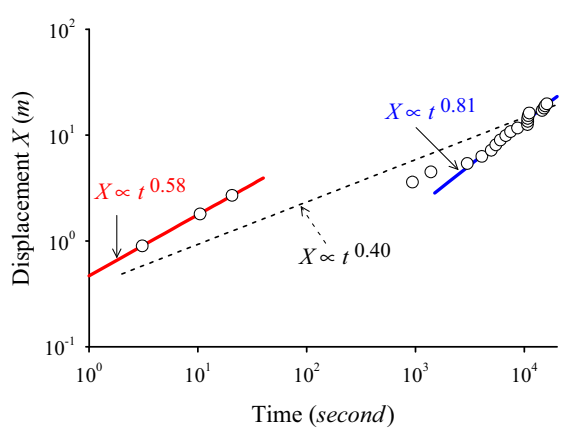

(b) Sediment size $3 \mathrm{~mm}$

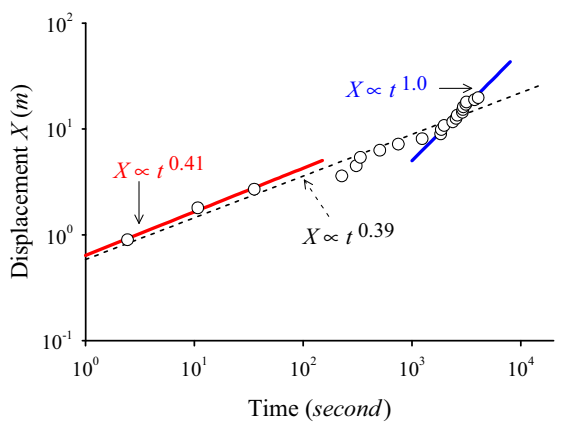

(c) Sediment size $7 \mathrm{~mm}$

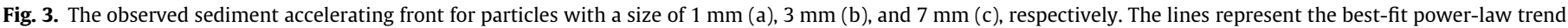

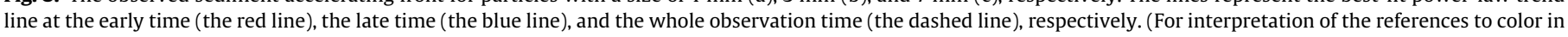
this figure legend, the reader is referred to the web version of this article.)

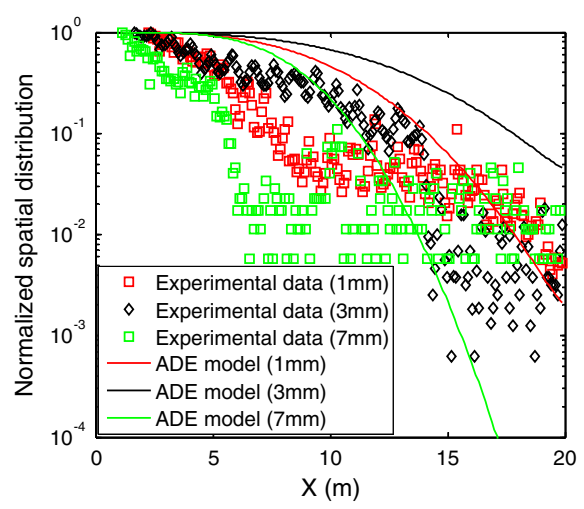

(a) semi-logarithmic graph

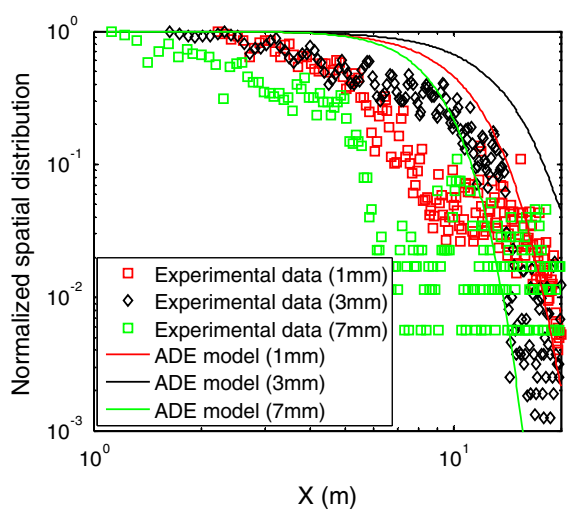

(b) double-logarithmic graph

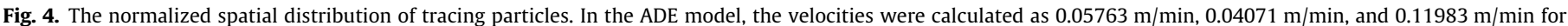
$1 \mathrm{~mm}, 3 \mathrm{~mm}$, and $7 \mathrm{~mm}$ particles, respectively. The best-fit dispersion coefficient $D$ is $0.04 \mathrm{~m}^{2} / \mathrm{min}$ for all experiments (see Table 3 ).

the distance from the source point to the $i$-th spatial interval, and $T$ is the half of flow duration. Fig. 4 shows that the classical ADE model cannot efficiently capture the observed sediment transport along a heterogeneous gravel-bed, which is consistent with previous findings (see for example, Bradley et al. (2010)).

\subsection{Sediment clusters and flow belts}

The micro-relief within an armor layer, such as the grain clusters, is observed in this study. Surface micro-structures on channel bed have been investigated by various researchers (Hassan and Church, 2000; Marion et al., 2003; Hendrick et al., 2010; Mao et al., 2011; Papanicolaou et al., 2012). Chen and Stone
(2008) found that the spatial heterogeneity of bed material is an intrinsic property even for a "well-mixed mixture". In the present experiments, sediment clusters are common characters in armor layers. Because the largest, $17 \mathrm{~mm}$ particles cannot resist hydraulic forces individually, they tend to agglomerate to form larger clusters. Fig. 5a and b show an example of linear and triangular structures on the flume-bed, respectively. Fig. 5c exhibits mixed-type clusters (outlined with red curves in Fig. 5c) where the largest particles resist hydraulic forces while the smaller particles add interlocking support. It is noteworthy that the "flow accelerating belts" (traced with blue curves in Fig. 5c) occur between the clusters. The clusters and flow belts were observed to be active rather than being static in spite of 


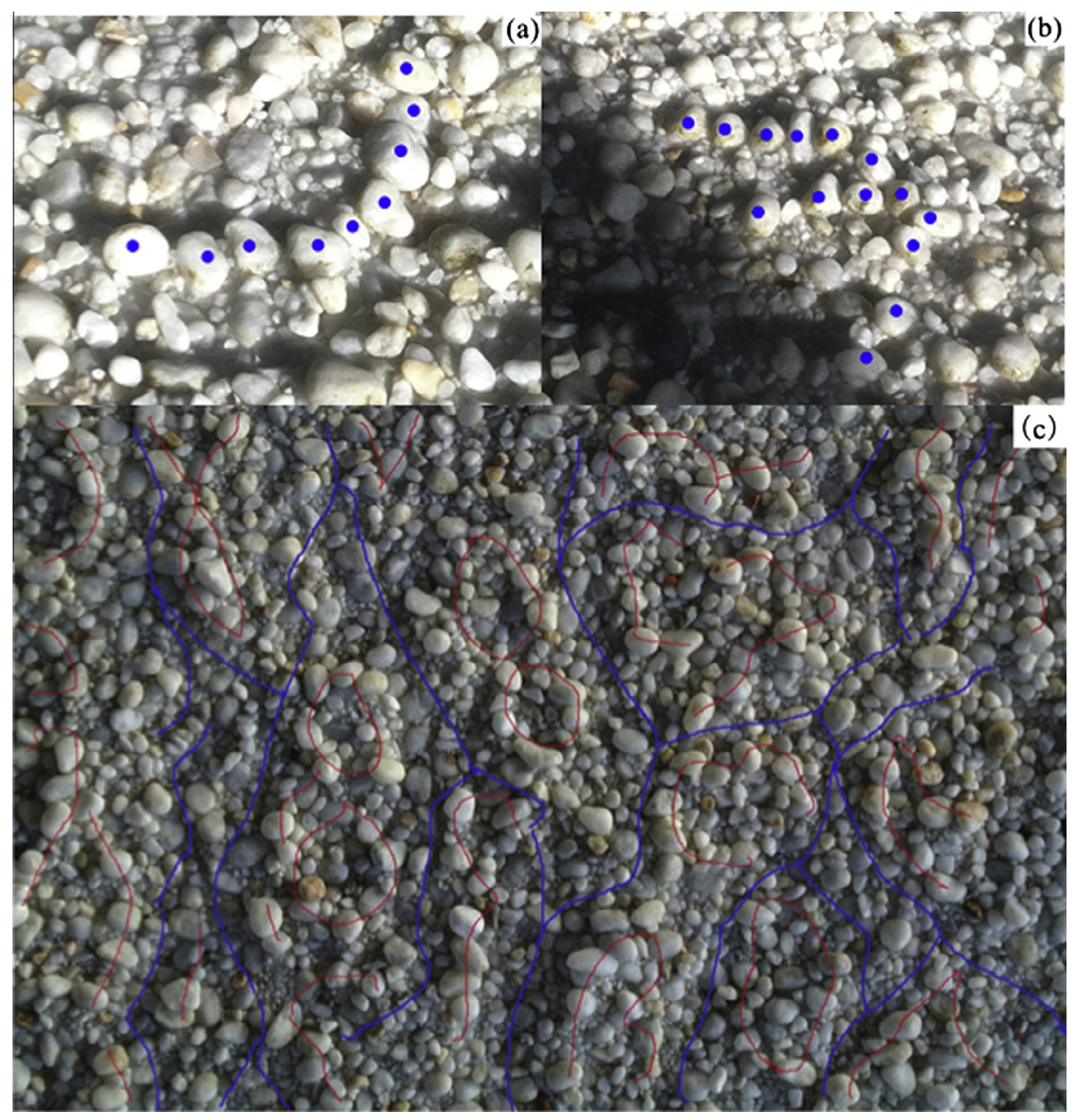

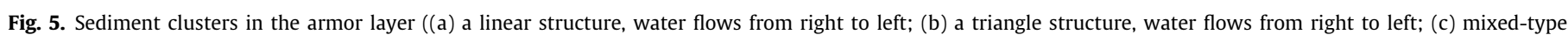
structures, water flows from up to down and "flow accelerated belts" come into being among those clusters).

the constant inflow, since occasionally they collapsed due to a current of turbulence and then re-formed downstream.

The anomalous dynamics of sediment particles may be related to both the grain clusters and flow belts. Accompanied with the process mentioned above, the finer particles previously trapped by the broken-down clusters may experience a sudden release and they might travel considerably far along the "flow accelerating belts" until they were re-captured by other clusters. Therefore the coarsening and structured bed surface allowed a co-existence of motionless periods (or sub-diffusion due to the trapping of clusters) and fast displacement (or non-local movement along the flow belts) of finer particles. Shen and Lu (1983) have also pointed out the fact that large particles not only have a sheltering effect on the smaller particles behind them, but also create other effects including secondary flow, horseshoe vortex, and possible increase of the turbulence intensity. Particles moving intermittently on the heterogeneous bed surface can therefore experience a bi-modal transport that cannot be efficiently characterized by the traditional exposure and hiding theory, motivating the application of a stochastic model discussed in the next section.

It is also noteworthy that the observed transient scaling rate of sediment front (shown in Fig. 3) is consistent with particle dynamics estimated by the sediment cluster shown in Fig. 5 . When a particle is trapped by a sediment cluster, it may remain motionless; when the particle enters the "flow accelerating belts", it tends to move downflume relatively fast. The intermingled trapping and motion result in the transient scaling rate shown in Fig. 3.

\section{Stochastic model analysis}

Recently, Hill et al. (2010) suggested that the particle's heavytailed travel distance might be modeled by a fractional-derivative transport equation (Metzler and Klafter, 2000). The previous discussion has confirmed that the partial transport process of nonuniform bedload is time scale dependent (see for example, Nikora et al., 2002; Zhang et al., 2012). Moreover, the spatial nonlocal feature shown in Fig. 4 implies that the spatial fractional engine might be useful for sediment transport since the spatial fractional derivative term can capture the fast displacement of tracing particles. Therefore, to describe anomalous transport of bed-load sediment, we revise the fractional derivative advectiondispersion equation (fADE) model developed recently by Zhang et al. (2009) as follows.

$\frac{\partial^{\alpha} S}{\partial t^{\alpha}}=-v \frac{\partial S}{\partial x}+D \frac{\partial^{\beta} S}{\partial x^{\beta}}$

where $\alpha(0<\alpha \leqslant 1)$ is the index of the time fractional derivative and $\beta(1<\beta \leqslant 2)$ is the index of the space fractional derivative. The time fractional derivative term $\partial^{\alpha} S / \partial t^{\alpha}$ captures the scale dependency of sediment transport, and the space fractional derivative term $D \partial^{\beta} S / \partial x^{\beta}$ describes the heavy tailed transport of sediment toward downstream. The sediment transport along the flume can be simulated by solving the governing Eq. (3) associated with the boundary conditions $S(x=0, t)=1$ (representing the continuous and constant 


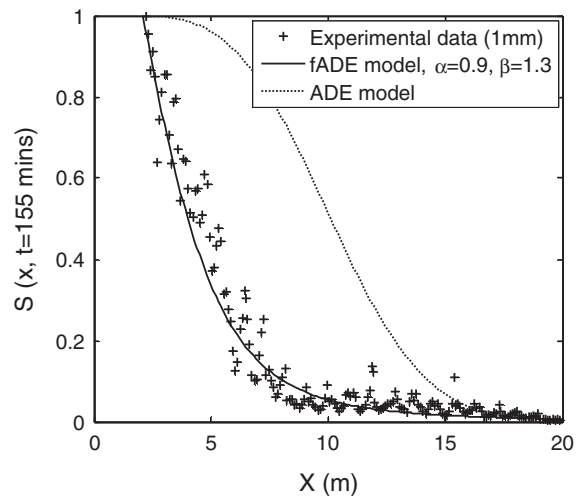

(a)

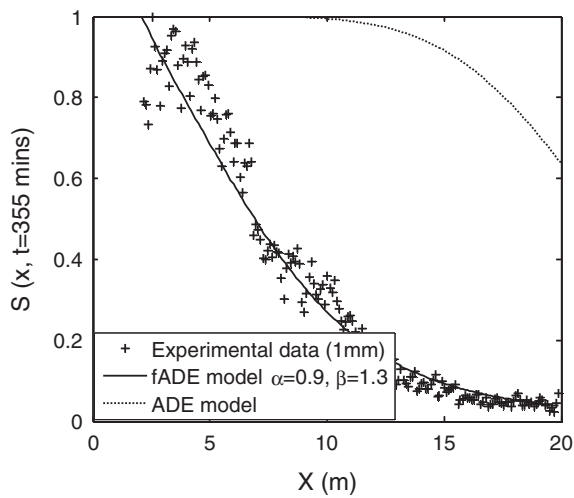

(b)

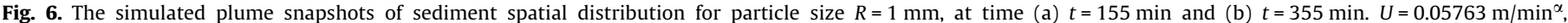
$D=0.04 \mathrm{~m}^{\beta} / \mathrm{min}^{\alpha}$.

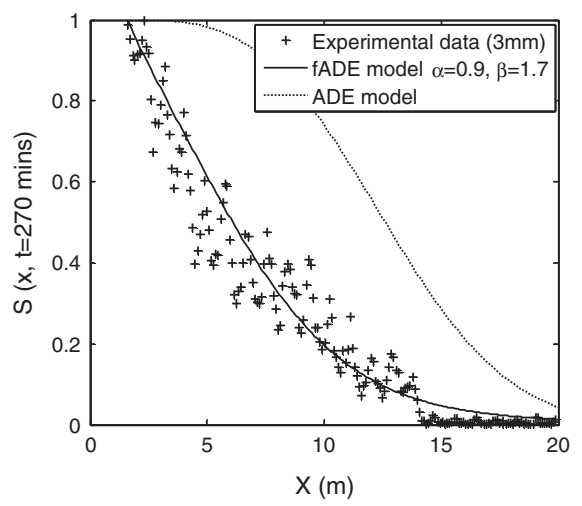

(a)

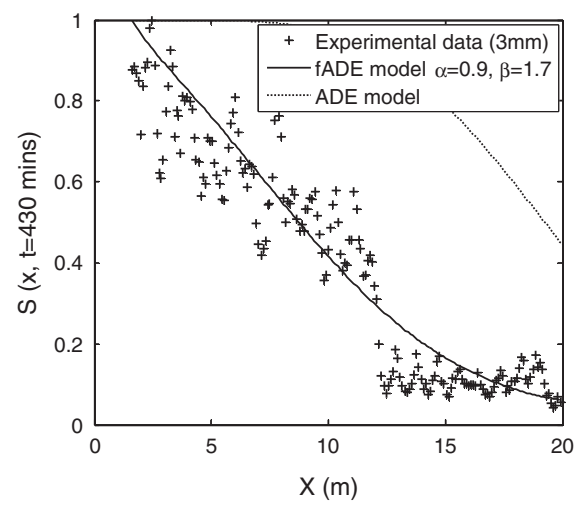

(b)

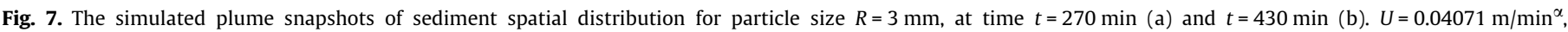
$D=0.04 \mathrm{~m}^{\beta} / \mathrm{min}^{\alpha}$.

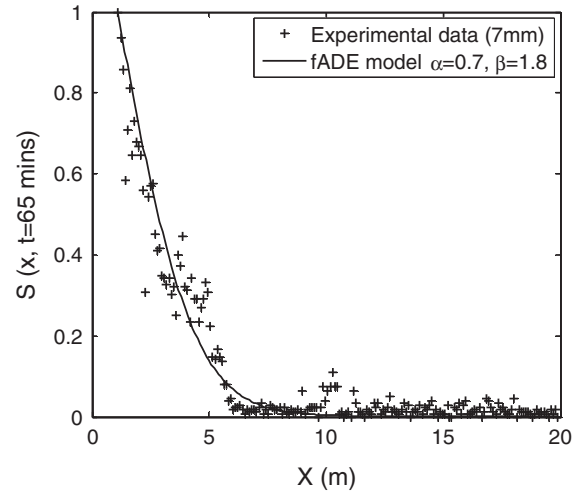

(a)

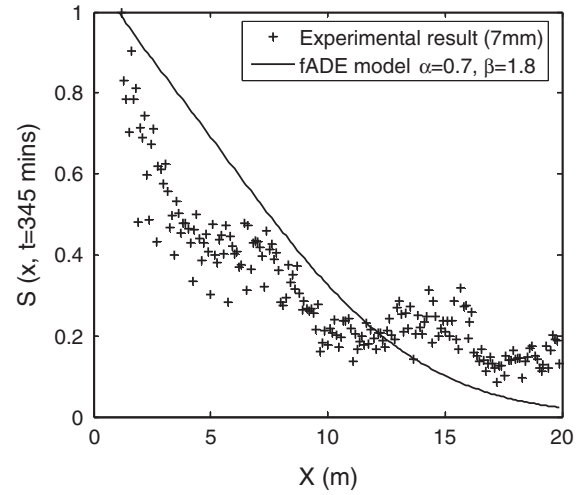

(b)

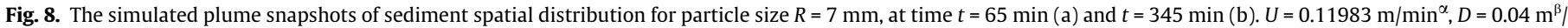
$\min ^{\alpha}$.

sediment input at the upstream boundary) and $\partial S(x, t) /\left.\partial t\right|_{x=20 m}=0$ (representing the zero gradient of sediment flux at the downstream boundary).

Figs. 6-8 show the best-fit and prediction results for three different particle sizes $\left(d_{m}=1 \mathrm{~mm}, 3 \mathrm{~mm}, 7 \mathrm{~mm}\right)$. Figs. 6a, 7a, and $8 \mathrm{a}$ use the data from the series-A experiments (Table 2) to calibrate the value of $D$ and the fractional derivative orders $\alpha$ and $\beta$. Figs. 6b,
$7 \mathrm{~b}$, and $8 \mathrm{~b}$ check the predictability of the fADE (Eq. (3)) with the calibrated $D, \alpha$ and $\beta$, using the measured data obtained from the series-B experiments (Table 2 ).

The best-fit $D, \alpha$, and $\beta$, and the calculated $v$ using Eq. (2) are listed in Table 3. For comparison purposes, the calculated curves by the ADE model (where the same values of $v$ and $D$ are used) are also plotted in Figs. 6 and 7. The ADE solutions for $7 \mathrm{~mm}$ 
Table 3

Model parameters for three particle sizes $\left(d_{m}=1 \mathrm{~mm}, 3 \mathrm{~mm}\right.$ and $\left.7 \mathrm{~mm}\right)$.

\begin{tabular}{lllll}
\hline $\begin{array}{l}\text { Mean } \\
\text { particle size } \\
d_{m}(\mathrm{~mm})\end{array}$ & $\begin{array}{l}\text { Mean } \\
\text { velocity } v \\
\left(\mathrm{~m} / \mathrm{min}^{\alpha}\right)\end{array}$ & $\begin{array}{l}\text { Dispersion } \\
\text { coefficient } D \\
\left(\mathrm{~m}^{\beta} / \mathrm{min}^{\alpha}\right)\end{array}$ & $\begin{array}{l}\text { Time } \\
\text { derivative } \\
\text { order } \alpha\end{array}$ & $\begin{array}{l}\text { Spatial } \\
\text { derivative } \\
\text { order } \beta\end{array}$ \\
\hline 1 & 0.05763 & 0.04 & 0.9 & 1.3 \\
3 & 0.04071 & 0.04 & 0.9 & 1.7 \\
7 & 0.11983 & 0.04 & 0.7 & 1.8 \\
\hline
\end{tabular}

particles deviate dramatically from the measurements and therefore were not added in Fig. 8.

The numerical simulation results shown in Figs. 6-8 indicate that the fADE model can reliably capture the observed sediment snapshots in series-A experiments, by fitting parameters $\alpha$ and $\beta$. The predicted snapshots (based on the fractional derivative model with parameters fitted by the series-A data) also agree well with the series-B experimental results. The fADE model with best-fit parameters at early times (such as time $T=155,270,65 \mathrm{~min}$ ), therefore, can offer effective late-time predictions (such as $T=355,430,345 \mathrm{~min}$ ) for different particle sizes.

The best-fit parameters listed in Table 3 show that the order of the time fractional derivative generally decreases with an increase in particle size. It illustrates that coarse particles are more sensitive to the travel history and particle trajectory. For example, on one hand, a large particle trapped by a sediment cluster at an early time may remain motionless with a high probability, which tends to enhance the overall sub-diffusion for sediment transport. On the other hand, a fine particle has more opportunities to enter the "flow accelerating belts", and move downstream relatively faster than coarse particles. Therefore, the finer sediment exhibits more super-diffusive feature in bed-load transport, which could also be observed from Table 3. It is worthy to emphasize that both suband super-diffusive features exist in bed-load transport for all sediment sizes, due to the co-existence of sediment clusters and preferential flow paths. Such distinct variations of velocities for particles moving intermittently along the heterogeneous bed surface lead to the heavy-tailed probability distribution of travel time/distance in sediment transport.

\section{Discussions}

\subsection{Sensitivity analysis of model parameters}

Here we investigate the sensitivity of the simulated sediment dynamics to main parameters in the fADE model (3), including the time index $\alpha$, the space index $\beta$, and the dispersion coefficient $D$.

Numerical experiments using the fADE model (3) show that the simulated sediment snapshot is sensitive to the index $\alpha$ (Fig. 9) (which dominates the trapping of sediment particles) and $\beta$ (Fig. 10) (which controls the large movement of bed-load particles). In particular, the simulated sediment snapshot of fine particles (with the size of $1 \mathrm{~mm}$ ) is sensitive to both the order of the space fractional derivative $\beta$ and the order of the time fractional derivative $\alpha$. The snapshot of the coarse particles ( $7 \mathrm{~mm}$ ), however, is more sensitive to $\alpha$ than to $\beta$. This discrepancy might be due to (1) the relatively smaller time index $\alpha$ fitted for the coarser particles, and (2) the relatively shorter experimental time (i.e., $65 \mathrm{~min}$ ) for the coarse sediments than the fine sediments (which is $155 \mathrm{~min}$ ). For the coarse sediments, the relatively small time index $\alpha$ constrains the time that particles spent in motion, and therefore the sediment particles could not travel a large distance within the relatively short observational time. Therefore, the snapshot for the coarse sediments may not be sensitive to $\beta$. This result is also consistent with the previous analysis which shows that the fine particles tend to exhibit super-diffusive feature and the coarse particles display mainly the sub-diffusive behavior.

Additional numerical results shown in Fig. 11 reveal that the simulated sediment snapshots are not sensitive to the dispersion coefficient $D$ in the fADE model. The leading edge of snapshots only enhanced slightly when $D$ increased from 0.03 to $0.05 \mathrm{~m}^{\beta} / \mathrm{min}^{\alpha}$, although a much larger $D$ leads to a heavier leading edge. In this study, the measured leading front of sediment snapshots accounts for a relatively small portion of the total mass, and therefore a large $D$ is not needed.

In summary, the above analysis shows that the anomalous dynamics of bed-load transport is sensitive to the index embedded in the fADE model (3). Model (3) captures the trapping effect of sediment transport using the time fractional derivative term with an index $\alpha$, and describes the fast displacement of the sediment front using the space fractional derivative term with an index $\beta$. By adjusting the two indices in the fADE model, one can conveniently capture a wide range of anomalous behavior for bed-load sediment transport.

\subsection{Limitations of the physical model and flume experiments}

The fADE model (3) has two major limitations in describing complex sediment dynamics. First, it is the scaling limit of a continuous time random walk process (Metzler and Klafter, 2000), which cannot be regarded as the governing equation of discrete

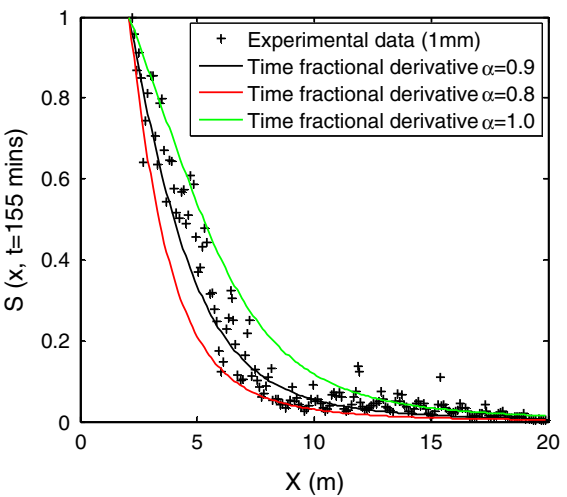

(a)

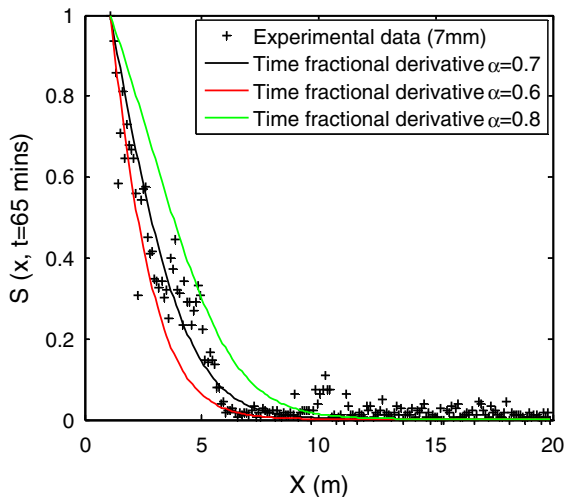

(b)

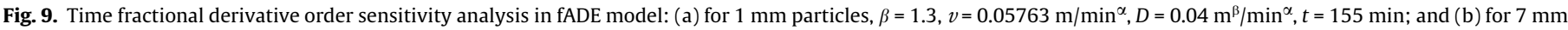
particles, $\beta=1.8, v=0.11983 \mathrm{~m} / \mathrm{min}^{\alpha}, D=0.04 \mathrm{~m}^{\beta} / \mathrm{min}^{\alpha}, t=65 \mathrm{~min}$. 


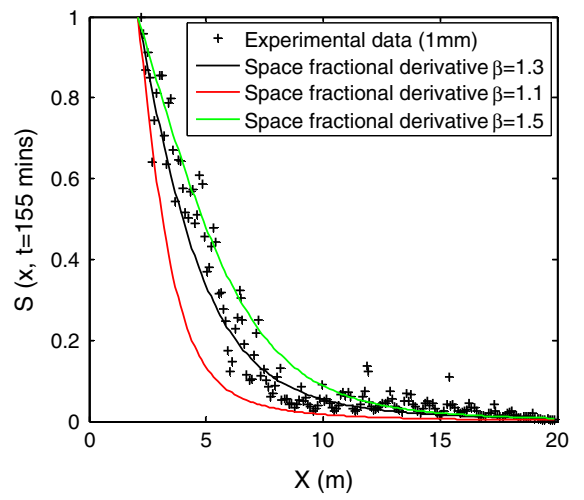

(a)

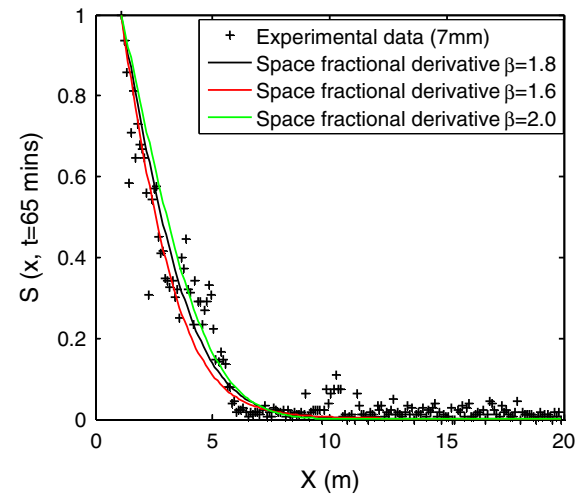

(b)

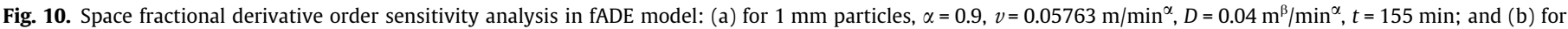
$7 \mathrm{~mm}$ particles, $\alpha=0.7, v=0.11983 \mathrm{~m} / \mathrm{min}^{\alpha}, D=0.04 \mathrm{~m}^{\beta} / \mathrm{min}^{\alpha}, t=65 \mathrm{~min}$.

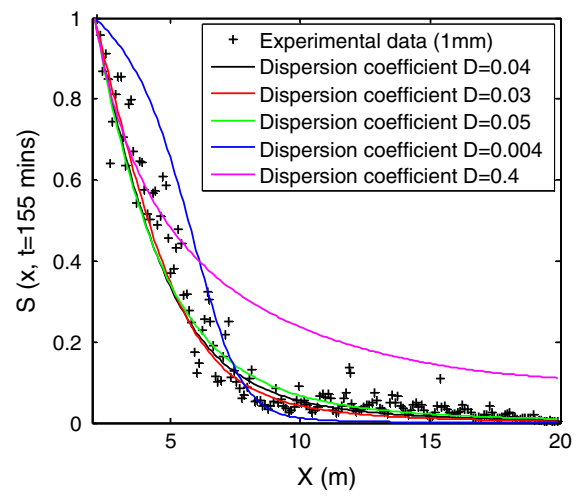

(a)

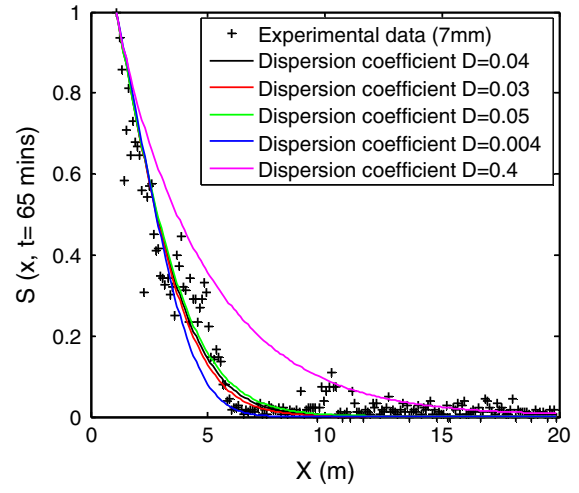

(b)

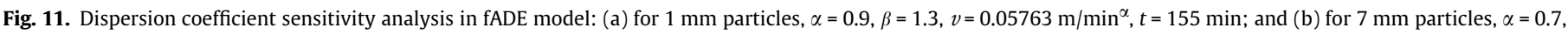
$\beta=1.8, v=0.11983 \mathrm{~m} / \mathrm{min}^{\alpha}, t=65 \mathrm{~min}$.

random walks that jump in time/space for a limited number of steps. The same constrain can be found for the classical 2nd-order $\mathrm{ADE}$ (1), which is the scaling limit for Brownian motion. It is not trivial, if not impossible, to build the partial different equation for random walkers with an arbitrary number of jumps. One possible solution is to develop a Lagrangian solver allowing particles to jump in space/time for any number of steps (Zhang et al., 2008), which logically generalizes the probability-based model for bedload transport proposed originally by Einstein (1937). We will explore this question in a future study. Second, the applicability of model (3) in capturing the exclusive temporal evolution of sediment dynamics (such as the one proposed by Nikora et al. (2002)) remains to be shown. The bed sediment transport documented in literature typically does not exhibit super-diffusion, since (1) the intermittent mobile/immobile process tends to truncate the continuous, large displacement of particles, and (2) the preferential flow path is scale dependent and therefore super-diffusion may only appear at a relatively small spatial scale. At a relatively large spatial and temporal scale, the mixture of large and small displacements of particles converges to a normal pdf, according to the central limit theory. We will explore the applicability of model (3) in large time scales in a future study.

In addition, we also noted that the plume snapshot predicted by the fADE model for the coarse particles $(7 \mathrm{~mm})$ is slightly worse than that for the fine and medium particles ( $1 \mathrm{~mm}$ and $3 \mathrm{~mm}$ ) (Figs. 6-8). This discrepancy might be due to the following reasons: (1) the influence of particle size cannot be completely captured by the employed fADE model; and (2) more experimental data are needed for a long-time period prediction (note that the time interval between two adjacent observations was larger for the $7 \mathrm{~mm}$ particles, compared with that for the $1 \mathrm{~mm}$ and $3 \mathrm{~mm}$ particles).

There are two major limitations of the flume experiments conducted in this study. First, the sediment snapshots were sampled in a limited time frame (varying from 65 to $430 \mathrm{~min}$ ), which cannot reveal the temporal evolution of tracer snapshots that are needed to further interpret the transient accelerating front and the temporal scaling of the overall dynamics. Second, the current sampling scheme does not distinguish sediment particles in the mobile or immobile phase. We will extend the flume experiments in a future study.

\section{Conclusion}

This study combines flume experiments and stochastic model analysis to explore the bedload sediment transport along heterogeneous sand beds. To improve our understanding of the anomalous dynamics for bedload sediment transport, we focus on the characteristics of the accelerating front and the influence of sediment size on transport. Four major conclusions are drawn from the above study.

(1) The accelerating front of bed sediment exhibits transient anomalous scaling rates deviating significantly from that of normal diffusion. In particular, when a particle is trapped 
for a relatively long period, the subsequent displacement tends to be super-diffusion, probably due to the preferential flow path that the particle can access after a long-period of trapping and adjustment. After upscaling, the transient anomalous scaling tends to be smeared (due to the spatial averaging), resulting in the overall sub-diffusive front for all particles. Upscaling therefore can smooth the small scale fluctuations, where the resultant dynamics might be approximated by a decoupled random walk model.

(2) Anomalous transport of bedload sediment is sensitive to the particle size. Finer sediment particles exhibit a relatively heavier leading edge, due probably to the size selective effect. Coarser particles can be trapped for a relatively longer time, and therefore exhibit a relatively stronger sub-diffusive pattern.

(3) Sediment clusters and flow belts between clusters may affect the dynamics of sediment particles. When the particle is trapped by a sediment cluster, it may remain motionless; when the particle enters the flow accelerated belts, it tends to move downstream relatively fast. The combined resting and motion processes explain the randomness in sediment transport, leading to the application of stochastic models.

(4) The fractional derivative model can capture the overall anomalous transport of sediment along heterogeneous sand beds. Time and fractional derivative orders $\alpha$ and $\beta$ are two key parameters to characterize the history-dependency and non-locality of anomalous sediment transport.

\section{Acknowledgements}

This research was supported by the National Science Foundation of China (11202066, 51279192), the "Hundred Talents Program" of the Chinese Academy of Science, and the National Science Foundation (NSF) under DMS-1025417 and DMS1460319. This paper does not necessarily reflect the view of the funding agencies. The experiments were conducted at China Institute of Water Resources and Hydropower Research, under the supervision of Professors Chunjing Liu and Wenhong Cao.

\section{References}

Barry, J.J., Buffington, J.M., King, J.G., 2004. A general power equation for predicting bed load transport rates in gravel bed rivers. Water Resour. Res. 40, W10401. http://dx.doi.org/10.1029/2004WR003190.

Bathurst, J.C., 2007. Effect of coarse surface layer on bed-load transport. J. Hydraul. Eng. 133 (11), 1192-1205.

Bettess, R., Frangipane, A., 2003. A one-layer model to predict the time development of static armour. J. Hydraul. Res. 41 (2), 179-194.

Bradley, D.N., Tucker, G.E., Benson, D.A., 2010. Fractional dispersion in a sand bed river. J. Geophys. Res. 115, F00A09. http://dx.doi.org/10.1029/2009JF001268.

Chen, L., Stone, M.C., 2008. Influence of bed material size heterogeneity on bedload transport uncertainty. Water Resour. Res. 44, W01405. http://dx.doi.org/ 10.1029/2006WR005483.

Chien, N., Wan, Z., 1999. Mechanics of Sediment Transport. Translated Under the Guidance of John S. McNown. ASCE Press.

Diplas, P., Shaheen, H., 2007. Bed load transport and streambed structure in gravel streams. Dev. Earth Surf. Proc. 11, 291-308.

Einstein, H.A., 1937. Bed Load Transport as a Probability Problem, Ph.D. thesis, ETH Zurich.

Garde, R.J., Al-Shaikh-Ali, K., Diette, S., 1977. Armoring process in degrading streams. J. Hydraul. Div. ASCE 103 (9), 1091-1095.

Gessler, J., 1970. Self stabilizing tendencies in alluvial channels. J. Waterways Harbours Div., Proc, ASCE 96 (WW2), 235-249.

Hassan, M.A., Church, M., 2000. Experiments on surface structure and partial sediment transport on a gravel bed. Water Resour. Res. 36 (7), 1885-1585.

Hendrick, R.R., Ely, L.L., Papanicolaou, A.N., 2010. The role of hydrologic processes and geomorphology on the morphology and evolution of sediment clusters in gravel-bed rivers. Geomorphology 114, 483-496.
Hill, K.M., Dellangelo, L., Meerschaert, M.M., 2010. Heavy-tailed travel distance in gravel bed transport. J. Geophys. Res. 115 (14), F00A14.

Janssen, S.R., 2010. A Part of Transport: Testing Sediment Transport Models Under Partial Transport Conditions. Thesis for University of Twente, Enschede, the Netherlands.

Karim, M.F., Holly, F.M., 1986. Armoring and sorting simulation in alluvial rivers. J. Hydraul. Eng., ASCE 112 (8), 705-715.

Lajeunesse, E., Malverti, L., Charru, F., 2010. Bed load transport in turbulent flow at the grain scale: experiments and modeling. J. Geophys. Res. 115, F04001. http:// dx.doi.org/10.1029/2009JF001628.

Lane, E.W., 1947. Report on the subcommittee on sediment terminology. Trans. Am. Geophys. Union 28 (6), 936-938.

Lee, H.Y., Odgaard, A.J., 1987. Simulation of bed armoring in alluvial channels. J. Hydraul. Eng. 112 (9), 794-801.

Little, W.C., Meyer, P.G., 1976. Stability of channel beds by armoring. J. Hydraul. Div. 102 (11), 1647-1661.

Mao, L., Cooper, J., Frostick, L., 2011. Grain size and topographical differences between static and mobile armour layers. Earth Surf. Proc. Land. 36 (10), 1321 1334.

Marion, A., Tait, S.J., McEwan, I.K., 2003. Analysis of small-scale gravel bed topography during armouring. Water Resour. Res. 39 (12), 1334. http:// dx.doi.org/10.1029/2003WR002367.

Martin, R.L., Jerolmack, D.J., Schumer, R., 2012. The physical basis for anomalous diffusion in bed load transport. J. Geophys. Res. 117, F01018. http://dx.doi.org/ 10.1029/2011JF002075.

Metzler, R., Klafter, J., 2000. The random walks guide to anomalous diffusion: a fractional dynamics approach. Phys. Report 339 (1), 1-77.

Nikora, V., Habersack, H., Huber, T., McEwan, I., 2002. On bed particle diffusion in gravel bed flows under weak bed load transport. Water Resour. Res. 38 (6), 1081. http://dx.doi.org/10.1029/2001WR000513.

Papanicolaou, A.N., Tsakiris, A.G., Strom, K.B., 2012. The use of fractals to quantify the morphology of cluster microforms. Geomorphology 139-140, 91-108.

Parker, G., 1990. Surface-based bedload transport relation for gravel rivers. J. Hydraul. Res. 28 (4), 417-436.

Parker, G., Sutherland, A.J., 1990. Fluvial armor. J. Hydraul. Res. 28 (5), 529-544.

Parker, G., Wilcock, P.R., 1993. Sediment feed and recirculating flumes: a fundamental difference. J. Hydraul. Eng. ASCE 119 (11), 1192-1204.

Parker, G., Dhamotharan, S., Stefan, H., 1982. Model experiments on mobile, paved gravel bed streams. Water Resour. Res. 18 (5), 1395-1408.

Proffitt, G.T., 1980. Selective Transport and Armoring of Nonuniform Alluvial Sediment. Rep. No. 80/22, Dept. Civil Engineering, Canterbury, New Zealand, 203.

Shaheen, H., Diplas, P., 2005. Bedload transport in gravel streams-surface versus subsurface based transport analysis. An-Najah Univ. J. Res. (N. Sc.), 19, 99-116.

Shen, H.W., Lu, J.Y., 1983. Development and prediction of bed armoring. J. Hydraul. Eng. 109 (4), 611-629.

Strom, K., Papanicolaou, A.N., Evangelopoulos, N., Odeh, M., 2004. Microforms in gravel bed rivers: formation, disintegration, and effects on bedload transport. J. Hydraul. Eng. 130 (6), 554-567.

Sutherland, A.J., Williman, E.B., 1977. Development of armoured surfaces in alluvial channels. In: 6th Australasian Hydraulics and Fluid Mechanics Conference, Adelaide, Australia.

Whiting, P.J., King, J.G., 2003. Surface particle sizes on armoured gravel streambeds: effects of supply and hydraulics. Earth Surf. Proc. Land. 28, 1459-1471.

Wilcock, P.R., 2001. Toward a practical method for estimating sediment-transport rates in gravel-bed rivers. Earth Surf. Proc. Land. 26, 1395-1408.

Wilcock, P.R., Crowe, J.C., 2003. Surface-based transport model for mixed-size sediment. J. Hydraul Eng. 129 (2), 120-128.

Wilcock, P.R., DeTemple, B.T., 2005. Persistence of armor layers in gravel-bed streams. Geophys. Res. Lett. 32, L08402.

Wilcock, P.R., McArdell, B.W., 1997. Partial transport of a sand/gravel sediment. Water Resour. Res. 33 (1), 235-245.

Wilcock, P.R., Kenworthy, S.T., Crowe, J.C., 2001. Experimental study of the transport of mixed sand and gravel. Water Resour. Res. 37 (12), 3349-3358.

Wittenberg, L., Newson, M.D., 2005. Particle clusters in gravel-bed rivers: an experimental morphological approach to bed material transport and stability concepts. Earth Surf. Proc. Land. 30, 1351-1368.

Wu, W.M., Wang, S.S.Y., Jia, Y.F., 2000. Nonuniform sediment transport in alluvial rivers. J. Hydraul. Res. 38 (6), 427-434.

Wu, B.S., Molinas, A., Julien, P.Y., 2004. Bed-material load computations for nonuniform sediment. J. Hydraul Eng. 130 (10), 1002-1012.

Zhang, Y., Meerschaert, M.M., Baeumer, B., 2008. Particle tracking for timefractional diffusion. Phys. Rev. E 78, 036705.

Zhang, Y., Benson, D.A., Reeves, D.M., 2009. Time and space nonlocalities underlying fractional derivative models: Distinction and literature review of field-scale applications. Adv. Water Resour. 32, 561-581. http://dx.doi.org/10.1016/ j.advwatres.2009.01.008.

Zhang, Y., Meerschaert, M.M., Packman, A.I., 2012. Linking fluvial bed sediment transport across scales. Geophys. Res. Lett. 39, L20404. http://dx.doi.org/ 10.1029/2012GL053476. 